\title{
Artigo \\ Projeto de um sistema de iluminação autoalimentado de luzes LED para bicicletas
}

\author{
Sabrina Loiola de Morais ${ }^{[1]}$, Romênia Gurgel Vieira ${ }^{[2]}$ \\ [1] Universidade Federal Rural do Semi-árido; sabrinaloiola9@ gmail.com.br \\ ${ }^{[2]}$ Universidade Federal Rural do Semi-árido; romenia.vieira@ ufersa.edu.br
}

Recebido: 05/06/2019;

Aceito: 26/07/2019;

Publicado: 07/10/2019.

Resumo: Os problemas ambientais acarretados pelo descarte de materiais eletrônicos são uma preocupação constante, e uma forma de reduzir seu consumo e meios de tratamento adequado são frequentemente requeridos. Este trabalho tem como objetivo analisar e projetar um sistema de iluminação autoalimentado de luzes LED (light- emitting diode) para bicicletas de modo a servir como alternativa viável para redução do consumo de pilhas e baterias, incentivando a prática socioecológica e reduzindo custos do uso desses sistemas de iluminação. Esse projeto baseia-se na Lei de indução eletromagnética de Faraday, utilizando-se da variação do fluxo de campo magnético de ímãs sobre as rodas da bicicleta para acendimento das luzes e discorre sobre os materiais utilizados e suas respectivas funções e especificações. Aborda também as técnicas utilizadas para obtenção dos resultados. A pesquisa foi desenvolvida através da composição do sistema, descrevendo seus componentes e a montagem das peças. Os resultados apresentados se mostraram satisfatórios, indicando o bom funcionamento do conjunto, que pode ser aplicado em qualquer tipo de bicicleta.

Palavras-chave: bicicleta; luzes LED; indução eletromagnética.

\section{INTRODUÇÃO}

Desde o século XIX a bicicleta tem sido um meio de transporte popular em várias partes do mundo, por ser um tipo de deslocamento de baixo custo e de fácil manuseio e acesso. A bicicleta apresenta fatores positivos ao meio ambiente e aos usuários, e desta forma a cada dia número de adeptos a esse sistema aumenta. Apresenta um baixo custo de aquisição e manutenção, e é associada ao desenvolvimento sustentável pois não utiliza combustíveis fósseis, não exige grandes áreas para estacionamento ou vias de tráfego, além de estimular a prática de vida saudável.

Segundo Teutobike [1], um estudo realizado na cidade de Odense, Dinamarca em parceria com a Aalborg University, que contou com cerca de dois mil ciclistas participantes, metade com luzes LED instaladas e a outra metade sem, no grupo com as luzes instaladas, foi observada uma redução de cerca de $32 \%$ no número de acidentes e aumento da sensação de segurança em $85 \%$.

O sistema de iluminação presente na bicicleta serve como sinalização para outros veículos, forma de iluminação do caminho para o ciclista e é um equipamento de segurança essencial, embora não seja de uso obrigatório no Brasil. Um dos sistemas de iluminação mais usados atualmente compõe-se de pequenas luzes LED, alimentados por baterias simples.

Tendo em vista que uma das principais preocupações atuais é sobre o uso consciente da energia elétrica e outras formas não convencionais para sua obtenção, a cada dia novos métodos são implementados como alternativas viáveis para substituição de agentes nocivos como os derivados do petróleo. Outras questões ambientais, como a contaminação da água e o descarte de resíduos nocivos.

Segundo a Secretaria de Desenvolvimento da Produção do Ministério do Desenvolvimento, Indústria e Comércio Exterior, o Brasil gerou aproximadamente 1,100 mil toneladas de resíduos de equipamentos eletrônicos (REEE) pequenos em 2014 [2]. Os dados são do estudo Logística Reversa de Equipamentos Eletrônicos, que explica que a maioria dos resíduos são compostos por materiais como plástico, vidro e metais, 
que podem ser recuperados e retornados como insumo para a indústria de transformação. Já os metais pesados, tais como chumbo, cádmio e mercúrio devem ter tratamento especial porque podem causar danos ambientais e de saúde.

Tendo em vista que os tratamentos utilizados para o descarte, armazenamento e recuperação desses metais pesados são complicados e de alto custo, a diminuição no uso de pilhas e baterias é um benefício a longo prazo de bom retorno para o meio ambiente.

Diante deste contexto, procurando amenizar o problema do descarte de baterias e outros materiais pesados utilizados em dispositivos eletrônicos, este trabalho tem como objetivo construir e analisar um sistema de iluminação noturna sustentável de luzes LED para bicicletas, utilizando-se da lei da indução eletromagnética de Faraday. Apesar de ser uma tecnologia já existente no mercado, com um sistema de iluminação exclusivo para bicicletas e que permite o usuário não comprar mais baterias por uma grande quantidade de tempo, esse estudo objetiva à uma utilização caseira para pessoas leigas e de forma a diminuir os custos do sistema.

\section{MATERIAIS E MÉTODOS}

\subsection{Método}

Aplicando-se a Lei da indução eletromagnética de Faraday, os ímãs de neodímio foram postos nos raios do pneu da bicicleta, com o auxílio de pequenas chapas de ferro.

A bobina ficou posicionada de modo que os ímãs passassem muito perto, para que a concentração de campo magnético não se dispersasse. Por isso também a escolha da bobina com núcleo magnético, de acordo com [3] UFPR (2013, materiais elétricos). Na Figura 1, pode-se observar um esquema do projeto inteiro, semelhante ao montado.

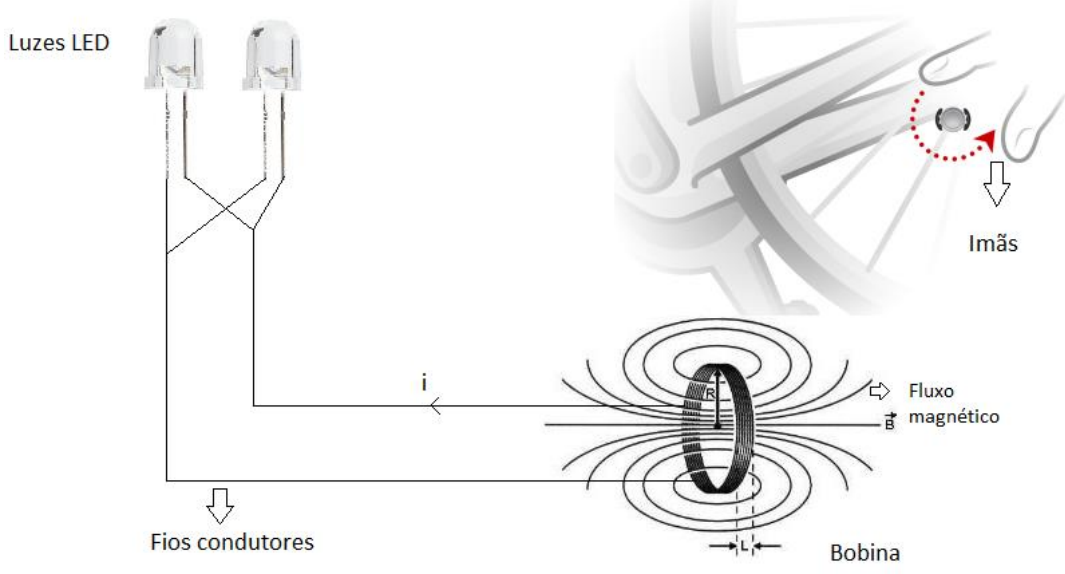

FIGURA 1. Esquema do sistema montado. (Autoria Própria)

A luz de LED vermelha ficou posicionada na parte posterior da bicicleta, de modo a cumprir sua função de sinalização para outros veículos. Ficando a cargo do ciclista o modo e local de posicionamento das luzes, não alterando em nada a geração do sistema. A luz foi conectada à bobina por fios condutores, como abordado anteriormente.

Com o sistema já montado e rotacionando o pneu da bicicleta, onde os ímãs estavam acoplados, houve variação da intensidade do campo magnético. Com a bobina posicionada próxima aos ímãs, fez-se valer o enunciado da Lei de Faraday, e uma corrente induzida foi gerada na bobina.

Através dos fios condutores, essa corrente induzida na bobina foi levada até o LED e ocorreu-se o acionamento da mesma. Nas Figuras 2.a e 2.b , pode-se observar o sistema experimental montado, no todo e aproximado. 


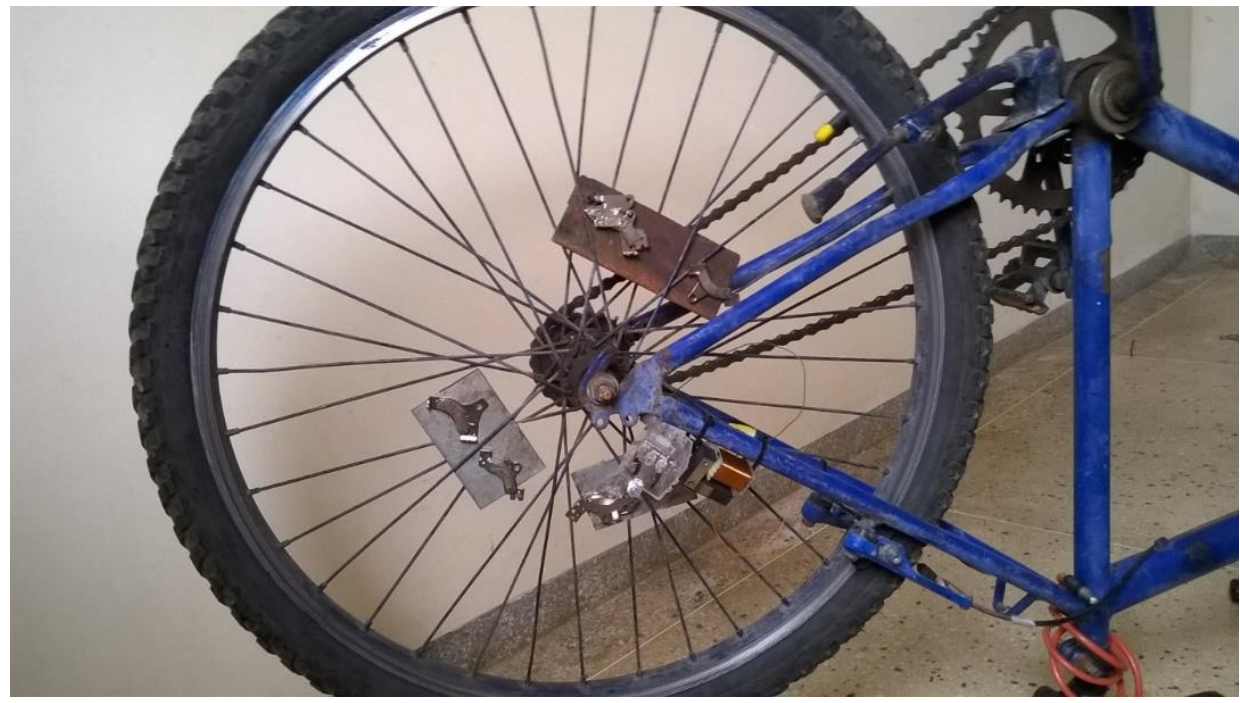

FIGURA 2.A. Sistema experimental. (Autoria própria)

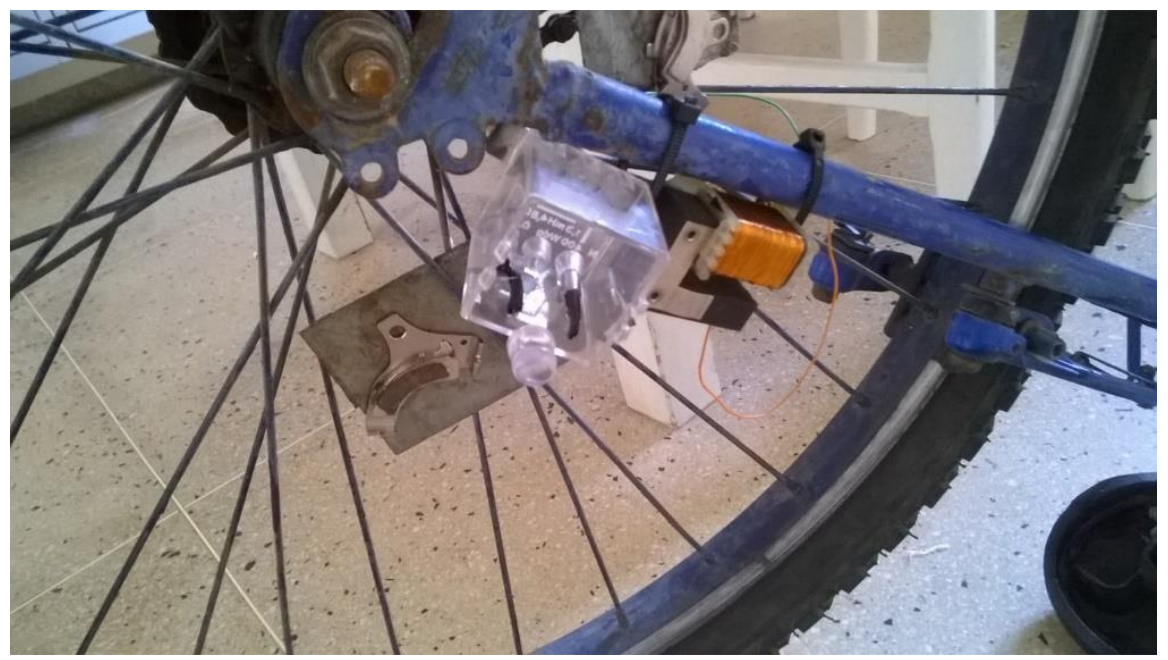

FIGURA 2.B. Sistema experimental aproximado. (Autoria própria)

\subsection{Materiais}

Os materiais utilizados no sistema foram escolhidos pensando-se de forma a reduzir os custos do sistema e o reaproveitamento de materiais descartados.

- 12 ímãs de neodímio;

Imãs usados para a variação da intensidade do campo magnético, reutilizados de discos rígidos descartados. Foram escolhidos ímãs de neodímio, pois são os ímãs permanentes com maior intensidade de campo, mais leves e podem levantar milhares de vezes seu próprio peso. Na Figura 3, ilustra-se o ímã usado no experimento. 


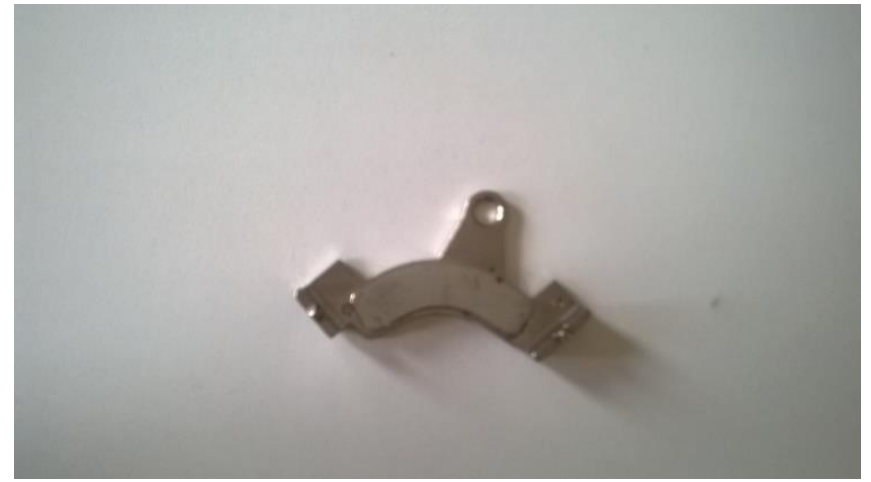

FIGURA 3. Imã de neodímio. (Autoria própria)

- 1 bobina com núcleo magnético de ferrita;

Bobina usada para indução da corrente gerada pela variação da intensidade do campo magnético dos ímãs. Reaproveitada de uma sucata de eletrodomésticos usados. Na Tabela1 abaixo, as especificações técnicas da bobina, retiradas da própria bobina em questão e na Figura 4, ilustra-se a bobina utilizada no experimento.

TABELA 1. Especificações da bobina. (Autoria própria)

\begin{tabular}{|c|c|c|c|}
\hline Resistência $(\Omega)$ & Corrente máxima $(\mathrm{A})$ & Indutância $(\mathrm{mH})$ & Número de espiras \\
\hline 4,8 & 0,8 & 1,3 & 500 \\
\hline
\end{tabular}

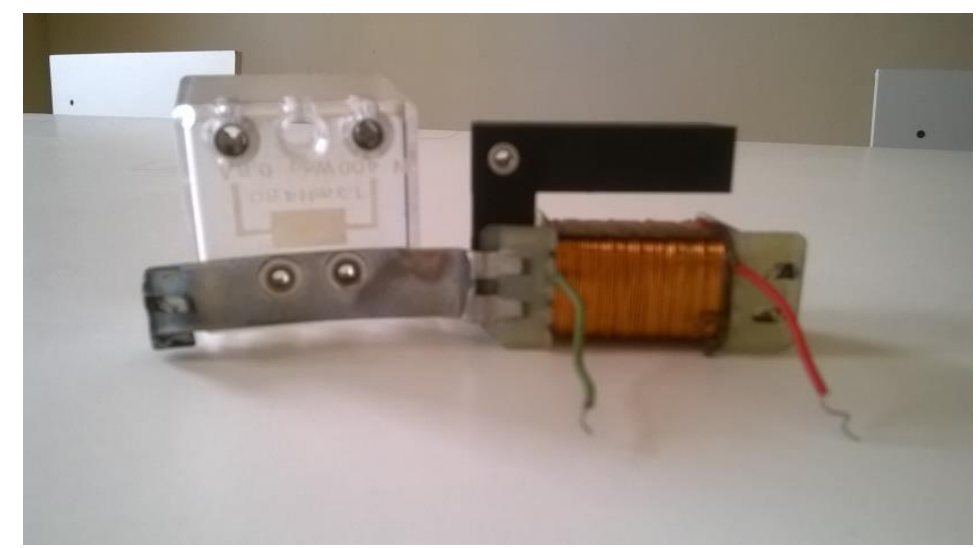

FIGURA 4. Bobina com núcleo de ferrita. (Autoria própria)

- Condutores;

Fios utilizados para condução da corrente induzida na bobina até as luzes. Na Figura 5, ilustra-se os condutores utilizados no experimento.

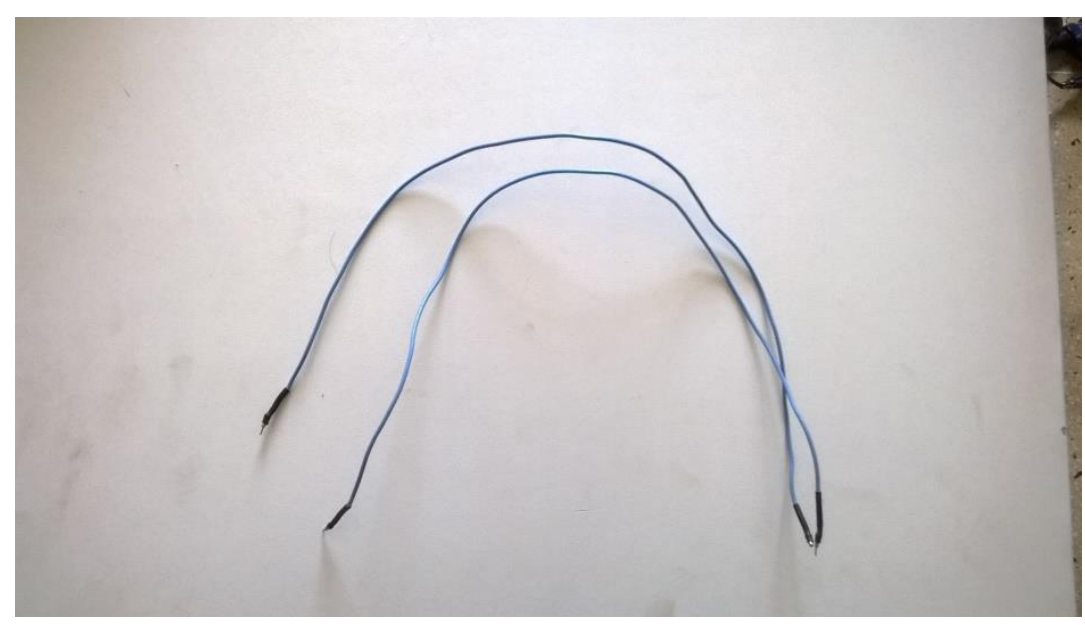

FIGURA 5. Fios condutores. (Autoria própria) 
- 1 luz LED vermelha;

Dispositivo utilizado para a iluminação da parte traseira da bicicleta. Na Figura 6, ilustra-se a luz utilizada no experimento e na tabela 2 , as especificações técnicas do LED.

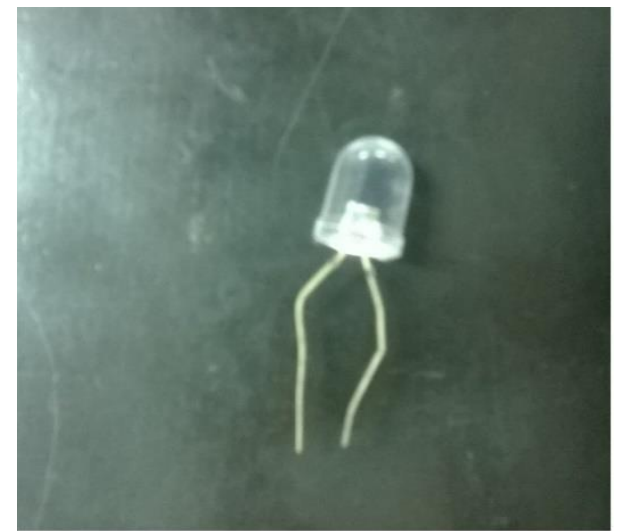

FIGURA 6. LED vermelho. (Autoria própria)

Tabela 2. Especificações do LED. (Autoria própria)

\begin{tabular}{|c|c|c|}
\hline Cor & Tensão $(\mathrm{V})$ & Corrente máxima $(\mathrm{A})$ \\
\hline Vermelho & 1,8 & 0,02 \\
\hline
\end{tabular}

\section{RESULTADOS E DISCUSSÃO}

Após o procedimento de montagem descrito no item 2.5 e certificando que todos os componentes funcionavam e se encontravam em seus respectivos lugares, foram realizadas medições de modo a comprovar o acionamento das luzes e certificar o funcionamento do sistema.

Os testes foram feitos com a bicicleta com os pneus para cima. Rotacionando o pneu traseiro com o auxílio dos pedais e com o auxílio de um multímetro digital acoplado na bobina, comprovou-se a existência de uma força eletromotriz presente na bobina. A corrente induzida na bobina foi direcionada ao LED pelos fios condutores e ocorreu-se o acionamento.

O LED vermelho utilizado no sistema é de $1,8 \mathrm{~V}$, ou seja, precisa de pelo menos essa tensão para seu acendimento. Depois de realizadas as medições, os dados encontrados encontram-se na tabela 3 abaixo:

TABEla 3. Medições. (Autoria Própria)

\begin{tabular}{|c|c|c|}
\hline Tensão máxima $(\mathrm{V})$ & Corrente máxima $(\mathrm{A})$ & Número de voltas \\
\hline 1,9 & 0,015 & 1,5 \\
\hline
\end{tabular}

A tensão medida na bobina foi muito próxima à tensão nominal de funcionamento do LED, o que acarreta em uma não dependência do uso de resistor, que pode ser calculado pela seguinte equação:

$$
\mathrm{R}=\frac{\mathrm{V}}{\mathrm{I}}
$$

Onde: $\quad \mathrm{R}=$ resistência;

$$
\begin{aligned}
& \text { V = tensão; } \\
& \text { I = corrente; }
\end{aligned}
$$

A tensão $V$ utilizada na equação 6 é determinada pela subtração entre a tensão presente na bobina e a tensão máxima permitida pelas especificações do LED. A corrente $I$ utilizada na Equação 6, é a corrente máxima permitida pelas especificações do LED. A resistência calculada foi de $5 \Omega$, considerada relativamente baixa e que não acarreta em risco de queima para o dispositivo.

Para garantir que dispositivo de iluminação LED não se danificará, a corrente máxima circulando no sistema não pode ultrapassar a corrente máxima prevista nas especificações do dispositivo. 
A tensão gerada na bobina pelos ímãs é alternada, o que implica em um formato de sinal de entrada do tipo senoidal, como ilustra a Figura 7.

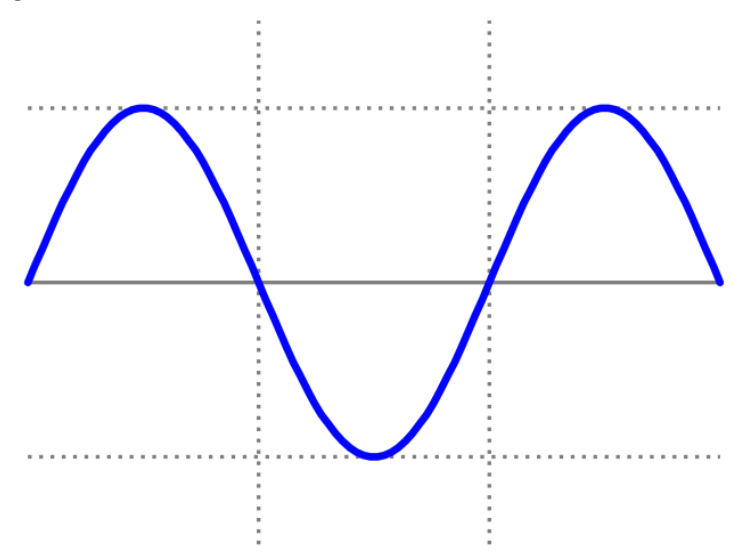

FIGURA 7. Sinal de entrada (Dispositivos eletrônicos - Boylestad) [4]

Porém, o diodo emissor de luz, como abordado anteriormente, é um dispostivo eletrônico que somente funciona quando polarizado diretamente. Ou seja, o semi-ciclo negativo do formato de onda senoidal que cosnta na Figura 14, não é reconhecido pelo diodo e esse não acende. O LED só acende quando encontra-se no semiciclo positivo. O sinal de saída do sistema constará como ilustra a Figura 8.

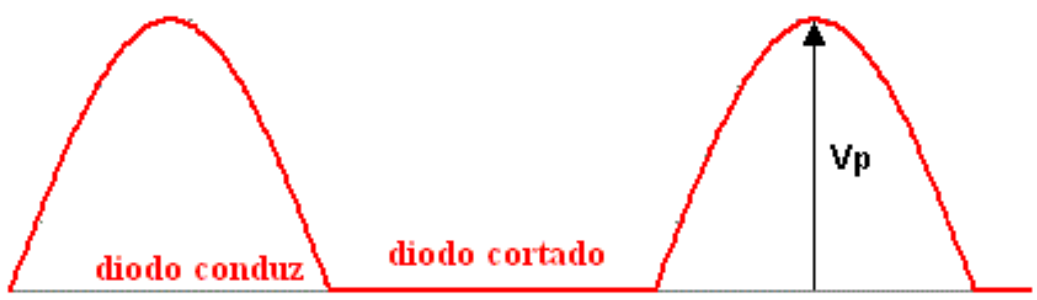

Figura 8. Sinal de saída. (Dispositivos eletrônicos - Boylestad)

Por atuar somente no semi-ciclo positivo do sinal de entrada, o LED emitirá um sinal luminoso com intervalos de tempo, ou seja, não será um sinal contínuo. A luz piscará conforme o diodo passe do estado de polarizado diretamente para polarizado reversamente (em corte).

Esse tipo de sinal luminoso não prejudica o objetivo do sistema, que é de sinalização. O sinal luminoso na traseira da bicicleta deve ser, de fato, alternado.

\section{CONCLUSÕES}

O trabalho elaborado apresentou uma proposta de um sistema de iluminação autoalimentado de luzes LED para bicicletas, de modo a diminuir os impactos ambientais causados pelo uso de baterias e materiais eletrônicos e de forma a implementar um sistema alternativo e economicamente viável para todos os tipos de usuários. A ideia inicial de utilizar também luzes brancas no projeto não foi possível devido à sua tensão específica maior e não condições de suprimento pelos ímãs utilizados.

Desta forma, o trabalho foi desenvolvido e testado em laboratório, como uma alternativa para o sistema de iluminação traseira. $\mathrm{O}$ sistema montado mostrou resultados satisfatórios e atendeu às expectativas. O sistema é de fácil entendimento e utiliza componentes simples e retirados de materiais descartados, diminuindo os custos e enfatizando seu cerne principal que é de reutilização de materiais, evitando descarte inadequado na natureza. Assim, é possível afirmar que o sistema é confiável e pode ser usado em sistemas de iluminação em movimento por todo e qualquer ciclista.

Esse trabalho é apenas um sistema inicial de luzes para bicicletas e fica aberto para trabalhos futuros a implementação das luzes brancas, bem como quaisquer melhorias e/ou acréscimos de funções ou dispositivos com o objetivo de melhorar seu funcionamento. 


\section{REFERÊNCIAS}

[1] TEUTOBIKE - Ciclismo urbano, 2014. [Internet] Disponível em: <http://www.teutobike.com.br/ciclismo-urbano/reelight-sl-250.html>. Acesso em: 25/04/2017

[2] PORTAL BRASIL - Resíduos Eletrônicos, 2014. [Internet] Disponível em: <http://www.brasil.gov.br/economia-e-emprego/2014/02/estudo-sobre-logistica-deresiduos-eletronicose-divulgado>. Acesso em: 08/02/2017

[3] UFPR - Materiais elétricos, 2013. [Internet] Disponível em: <http://www.eletrica.ufpr.br/pedroso/2011/TE144/Aulas/MateriaisEletricos.pdf >. Acesso em: 25/04/2017

[4] BOYLESTAD, Robert L., NASHELSKY, Louis - DISPOSITIVOS ELETRÔNICOS - Teoria de Circuitos - 8 ed. São Paulo: Prentice Hall. 2005. p 3-24 